\title{
A problematização
}

\section{$e$ a aprendizagem baseada}

\author{
em problemas:
}

\section{diferentes termos ou diferentes caminhos?}

\author{
Neusi Aparecida Navas Berbel ${ }^{1}$
}

\begin{abstract}
BERBEL, N. N.: "Problematization" and Problem-Based Learning: different words or different ways? Interface Comunicação, Saúde, Educação, v.2, n.2, 1998.
\end{abstract}

Two important new proposals are described and analyzed: Methodology of Problematization and Problem-Based Learning. The two proposals, which develop from distinct theories, have common and divergent points. However, according to both proposals, teaching and learning develop from problems. According to Methodology of Problematization, the students are led to identify the problems from a certain reality, while according to Problem-Based Learning, the problems are formulated by specialists, so that they involve all the disciplines which compose a certain curriculum. Although these two proposals are different, they provide the students with new opportunities to learn.

Keywords : Problem-Based Learning; Teaching.

Duas importantes propostas inovadoras são objeto de descrição e análise comparativa: a Metodologia da Problematização e a Aprendizagem Baseada em Problemas. As duas propostas, que se desenvolvem a partir de visões teóricas distintas, têm pontos comuns e pontos diferentes. Nas duas propostas, o ensino e a aprendizagem ocorrem a partir de problemas. Na Metodologia da Problematização, enquanto alternativa de metodologia de ensino, os problemas são extraídos da realidade pela observação realizada pelos alunos. Na Aprendizagem Baseada em Problemas, enquanto proposta curricular, os problemas de ensino são elaborados por uma equipe de especialistas para cobrir todos os conhecimentos essenciais do currículo. O conhecimento de suas características não permite confundi-las, mas, com certeza, tomá-las como alternativas inspiradoras de um ensino inovador que ultrapasse a abordagem tradicional.

Palavras-Chave : Aprendizado Baseado em Problemas; Ensino.

\footnotetext{
${ }^{1}$ Professora do Departamento de Educação da Universidade Estadual de Londrina - UEL. Londrina /PR.
} 


\section{Introdução}

Algumas escolas que preparam profissionais para a área da saúde têm surpreendido a comunidade interna e externa com inovações importantes na maneira de pensar, organizar e desenvolver seus cursos.

Inspirados em exemplos de experiências de mais de 30 anos, realizadas no Canadá ( em MacMaster) e na Holanda (em Maastricht) principalmente, e também por recomendação das Sociedades das Escolas Médicas para países da África, Ásia e América Latina, várias escolas de Medicina no Brasil vêm buscando adotar a Aprendizagem Baseada em Problemas (Problem Based Learning - PBL) em seus currículos.

Paralelamente, cursos de Enfermagem nos Estados do Rio de Janeiro, Minas Gerais, São Paulo e Paraná têm realizado importante movimento de incorporação da Problematização em suas atividades curriculares normais e especiais. Tais práticas (com a Problematização) já vêm sendo utilizadas por quase duas décadas na preparação de Auxiliares de Enfermagem em serviço ou não, em Minas Gerais e Rio de Janeiro.

Na Universidade Estadual de Londrina - PR, há seis anos desenvolvem-se um projeto especial de ensino, na área da saúde, através da Problematização, tendo como referência o Método do Arco, de Charlez Maguerez (apud Bordenave, 1982).

Tais inovações têm tido repercussões importantes. Tanto as positivas, por suas características, pressupostos e conseqüências diferenciadas, provocadas pelo discurso e pela prática daqueles que passam a apreciar as novas maneiras de ensinar e de aprender, quanto as negativas, provocadas pelas resistências naturais às mudanças e também por aqueles que, apressados, fazem pequenas adaptações em suas práticas tradicionais (e então os resultados em geral não são os esperados) e passam a denominá-las inconvenientemente com os termos que aqui estamos considerando para análise e discussão - Aprendizagem Baseada em Problemas e Problematização.

Desejosos de disseminar tais práticas educativas para ampliá-las no ensino, enquanto propostas ou experiências, muitos são os que escrevem ou comentam sobre elas. Observamos uma variedade muito grande de termos com os quais são designadas, como por exemplo, técnica de ensino, método de ensino, metodologia, pedagogia, proposta pedagógica, proposta curricular, estratégia de ensino, currículo PBL, procedimento metodológico etc. 
Ainda observamos os que anunciam uma destas propostas com o nome da outra, considerando que se trata do mesmo assunto ou aqueles que julgam que o exercitar de uma das propostas é condição suficiente de preparo para a adoção da outra.

Tais constatações constituíram o desafio para a elaboração deste texto, com o qual pretendemos caracterizar a Problematização e a Aprendizagem Baseada em Problemas, para podermos, junto com o leitor, responder à questão do título que o anuncia: a Problematização e a Aprendizagem Baseada em Problemas são diferentes termos ou diferentes caminhos?

Empenhar-nos-emos em defender a tese de que são diferentes caminhos.

Para provar essa tese, buscaremos destacar os pontos em que se aproximam e os pontos em que se diferenciam as duas propostas.

Enquanto isso, vamos expondo ao leitor o nosso entendimento até o momento e que nos permite uma designação diferente para as duas propostas: a primeira - como Metodologia da Problematização e a segunda - provisoriamente como Proposta Curricular de Aprendizagem Baseada em Problemas (PBL) pela observação de como vem sendo adotada em escolas de Medicina da UNESPBotucatu, na FAMEMA-Marília, na UEL-Londrina, entre outras instituições do país.

Entendemos que a necessidade desta comunicação, que não pretende ser conclusiva mas provocativa, ocorre porque as duas propostas aqui consideradas trabalham intencionalmente com problemas para o desenvolvimento dos processos de ensinar e aprender. Esse fato facilita uma conclusão apressada ou equivocada por aqueles que ainda têm poucas informações sobre as duas propostas e as vêem superficialmente defendidas/explicadas por profissionais da saúde e mesmo da educação.

A Metodologia da Problematização: algumas características.

Vamos iniciar caracterizando a Metodologia da Problematização, conforme vimos formulando teórica e praticamente, nos últimos seis anos.

A primeira referência para essa Metodologia é o Método do Arco, de Charles Maguerez, do qual conhecemos o esquema apresentado por Bordenave e Pereira (1982). Nesse esquema constam cinco etapas que se desenvolvem a partir da realidade ou um recorte da realidade: Observação da Realidade; Pontos-Chave; 
Teorização; Hipóteses de Solução e Aplicação à Realidade (prática). De seu autor e do próprio esquema de Bordenave e Pereira não se obteve mais informações, o que nos estimulou a buscar um entendimento mais profundo para poder utilizálo amplamente.

Temos proposto a Metodologia da Problematização como metodologia de ensino, de estudo e de trabalho, para ser utilizada sempre que seja oportuno, em situações em que os temas estejam relacionados com a vida em sociedade.

Embora saibamos de sua utilização para cursos como um todo, principalmente quando diretamente relacionado com a prestação de serviços à comunidade, como é o caso da formação de Auxiliares de Enfermagem e de cursos para Gerentes de Enfermagem (como aconteceu na UEL em 1995), temos proposto a Metodologia da Problematização como uma alternativa metodológica apropriada para o Ensino Superior.

Estamos conscientes de que nem sempre é a alternativa mais adequada para certos temas de um programa de ensino. Não pensamos ensinar o uso de crase através da Problematização, nem a tradução de palavras do português para outra língua, ou o cálculo de certas expressões matemáticas... o que de social, ético, econômico ou político estaria aí implicado? Há certamente temas que serão mais bem aprendidos com uma ou mais alternativas metodológicas da imensa lista à nossa disposição na literatura pedagógica.

Então, quando oportuna, a Metodologia da Problematização pode ser desenvolvida como segue.

A primeira etapa é a Observação da Realidade social, concreta, pelos alunos, a partir de um tema ou unidade de estudo. Os alunos são orientados pelo professor a olhar atentamente e registrar sistematizadamente o que perceberem sobre a parcela da realidade em que aquele tema está sendo vivido ou acontecendo, podendo para isso serem dirigidos por questões gerais que ajudem a focalizar e não fugir do tema.

Tal observação permitirá aos alunos identificar dificuldades, carências, discrepâncias, de várias ordens, que serão transformadas em problemas, ou seja, serão problematizadas. Poderá ser eleito um desses problemas para todo o grupo estudar ou então vários deles, distribuídos um para cada pequeno grupo.

As discussões entre os componentes do grupo e com o professor ajudarão na redação do problema, como uma síntese desta etapa e que passará a ser a referência para todas as outras etapas do estudo. 
Para realizar as atividades da segunda etapa que é a dos Pontos-Chaves, os alunos são levados a refletir primeiramente sobre as possíveis causas da existência do problema em estudo. Por que será que esse problema existe?

Neste momento os alunos, com as informações que dispõem, passam a perceber que os problemas de ordem social (os da educação, da atenção à saúde, da cultura, das relações sociais etc.) são complexos e geralmente multideterminados. Continuando as reflexões, deverão se perguntar sobre os possíveis determinantes maiores do problema, que abrangem as próprias causas já identificadas. Agora, os alunos percebem que existem variáveis menos diretas, menos evidentes, mais distantes, mas que interferem na existência daquele problema em estudo.

Tal complexidade sugere um estudo mais atento, mais criterioso, mais crítico e mais abrangente do problema, em busca de sua solução. A partir dessa análise reflexiva, os alunos são estimulados a uma nova síntese: a da elaboração dos pontos essenciais que deverão ser estudados sobre o problema, para compreendêlo mais profundamente e encontrar formas de interferir na realidade para solucioná-lo ou desencadear passos nessa direção. Podem ser listados alguns tópicos a estudar, perguntas a responder ou outras formas. São esses pontos chaves que serão desenvolvidos na próxima etapa.

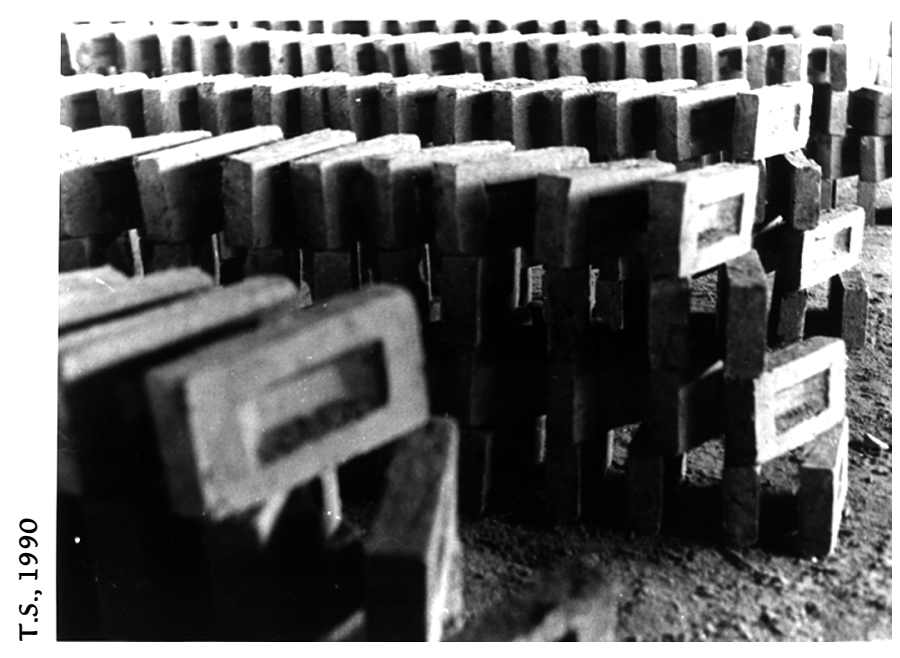

A terceira etapa é a da teorização. Esta é a etapa do estudo, da investigação propriamente dita. Os alunos se organizam tecnicamente para buscar as informações que necessitam sobre o problema, onde quer que elas se encontrem, dentro de cada ponto chave já definido. Vão à biblioteca buscar livros, revistas especializadas, pesquisas já realizadas, jornais, atas de congressos etc.; vão consultar especialistas sobre o assunto; vão observar o fenômeno ocorrendo; aplicam questionários para obter informações de várias ordens (quantitativas ou qualitativas); assistem palestras $e$ aulas quando oportunas etc.. 
As informações obtidas são tratadas, analisadas e avaliadas quanto a suas contribuições para resolver o problema. Tudo isto é registrado, possibilitando algumas conclusões, que permitirão o desenvolvimento da etapa seguinte.

A quarta etapa é a das hipóteses de solução. Todo o estudo realizado deverá fornecer elementos para os alunos, crítica e criativamente, elaborarem as possíveis soluções. O que precisa acontecer para que o problema seja solucionado? O que precisa ser providenciado? O que pode realmente ser feito?

Nesta metodologia, as hipóteses são construídas após o estudo, como fruto da compreensão profunda que se obteve sobre o problema, investigando-o de todos os ângulos possíveis.

A quinta e última etapa é a da Aplicação à Realidade. Esta etapa da Metodologia da Problematização ultrapassa o exercício intelectual , "pois as decisões tomadas deverão ser executadas ou encaminhadas. Nesse momento, o componente social e político está mais presente. A prática que corresponde a esta etapa implica num compromisso dos alunos com o seu meio. Do meio observaram os problemas e para o meio levarão uma resposta de seus estudos, visando transformá-lo em algum grau” (Berbel, 1996, p.8-9).

Completa-se assim o Arco de Maguerez, com o sentido especial de levar os alunos a exercitarem a cadeia dialética de ação - reflexão - ação, ou dito de outra maneira, a relação prática - teoria - prática, tendo como ponto de partida e de chegada do processo de ensino e aprendizagem, a realidade social.

Em síntese, a Metodologia da Problematização tem uma orientação geral como todo método, caminhando por etapas distintas e encadeadas a partir de um problema detectado na realidade. Constitui-se uma verdadeira metodologia, entendida como um conjunto de métodos, técnicas, procedimentos ou atividades intencionalmente selecionados e organizados em cada etapa, de acordo com a natureza do problema em estudo e as condições gerais dos participantes. Volta-se para a realização do propósito maior que é preparar o estudante/ser humano para tomar consciência de seu mundo e atuar intencionalmente para transformálo, sempre para melhor, para um mundo e uma sociedade que permitam uma vida mais digna para o próprio homem.

Com todo o processo, desde o observar atento da realidade e a discussão coletiva sobre os dados registrados, mas principalmente com a reflexão sobre as possíveis causas e determinantes do problema e depois com a elaboração de 
hipóteses de solução e a intervenção direta na realidade social, tem-se como objetivo a mobilização do potencial social, político e ético dos alunos, que estudam cientificamente para agir politicamente, como cidadãos e profissionais em formação, como agentes sociais que participam da construção da história de seu tempo, mesmo que em pequena dimensão.

Está presente, nesse processo, o exercício da praxis e a possibilidade de formação da consciência da praxis, como já buscamos demonstrar em texto anterior (Berbel, 1996, p.7-17).

\title{
A Proposta Curricular de Aprendizagem Baseada em Problemas e algumas de suas características
}

Conforme Sakai e Lima (1996), temos a seguinte apresentação sobre a Aprendizagem Baseada em Problemas:

\begin{abstract}
O PBL é o eixo principal do aprendizado teórico do currículo de algumas escolas de Medicina, cuja filosofia pedagógica é o aprendizado centrado no aluno. É baseado no estudo de problemas propostos com a finalidade de fazer com que o aluno estude determinados conteúdos. Embora não constitua a única prática pedagógica, predomina para o aprendizado de conteúdos cognitivos e integração de disciplinas. Esta metodologia é formativa à medida que estimula uma atitude ativa do aluno em busca do conhecimento e não meramente informativa como é o caso da prática pedagógica tradicional.
\end{abstract}

Encontramos importantes referências sobre a Aprendizagem Baseada em Problemas na Home Page da UEL, 1997 (http://www.uel.br/uel/pbl/). Nesse material lemos que, a partir de definições importantes relacionadas às finalidades do currículo do curso,

prepara-se um elenco de situações que o aluno deverá saber/ dominar. Este elenco é analisado situação por situação para que se determine que conhecimentos o aluno deverá possuir para cada uma delas. Este elenco constitui os temas de estudo. (...) Cada tema será transformado em um problema para ser discutido em um grupo tutorial, quando se tratar de um tema que diga respeito à esfera cognitiva. 
A construção do problema, conforme orientações seguidas pela Faculdade de Medicina da Universidade de Maastricht-Holanda, deve:

1. consistir de uma descrição neutra do fenômeno para o qual se deseja uma explicação no grupo tutorial; 2. ser formulado em termos concretos; 3.ser conciso; 4. ser isento de distrações; 5. dirigir o aprendizado a um número limitado de itens; 6 . dirigir apenas a itens que possam ter alguma explicação baseada no conhecimento prévio dos alunos; 7. exigir não mais que em torno de 16 horas de estudo independente dos alunos para que seja completamente entendido de um ponto de vista científico (complementação e aperfeiçoamento do conhecimento prévio). (Sakai e Lima, 1996)

Ao lado dos problemas, são organizadas situações para treinamento de habilidades psicomotoras, assim como estágios de várias complexidades, principalmente nos dois últimos anos - de internato. "A esfera cognitiva do Currículo PBL deve garantir que o aluno estude situações suficientes para se capacitar a procurar o conhecimento por si mesmo quando se deparar com uma situação problema ou um caso clínico".

A Aprendizagem Baseada em Problemas tem o grupo tutorial como apoio para os estudos. O grupo tutorial é composto de um tutor e 8 a 10 alunos. Dentre os alunos, um será o coordenador e outro será o secretário, rodiziando de sessão a sessão, para que todos exerçam essas funções. No grupo, os alunos são apresentados a um problema pré elaborado pela comissão de elaboração de problemas.

\footnotetext{
A discussão de um problema se desenrola em duas fases. $\mathrm{Na}$ primeira fase o problema é apresentado e os alunos formulam objetivos de aprendizado a partir da discussão do mesmo. $\mathrm{Na}$ segunda fase, após estudo individual realizado fora do grupo tutorial, os alunos rediscutem o problema à luz dos novos conhecimentos adquiridos. (http://www.uel.br/uel/pbl/)
}

Nesse mesmo documento lemos que o método, no grupo tutorial, é seguido em sete passos: 
1. Leitura do problema, identificação e esclarecimento de termos desconhecidos; 2. Identificação dos problemas propostos pelo enunciado; 3. Formulação de hipóteses explicativas para os problemas identificados no passo anterior (os alunos se utilizam nesta fase dos conhecimentos de que dispõem sobre o assunto); 4. Resumo das hipóteses; 5. Formulação dos objetivos de aprendizado ( trata-se da identificação do que o aluno deverá estudar para aprofundar os conhecimentos incompletos formulados nas hipóteses explicativas); 6. Estudo individual dos assuntos levantados nos objetivos de aprendizado; 7. Retorno ao grupo tutorial para rediscussão do problema frente aos novos conhecimentos adquiridos na fase de estudo anterior.

Uma carga horária é prevista para o estudo de cada problema. O grupo deve organizar-se para cumprir os sete passos acima descritos dentro desse tempoem geral umas quatro manhãs ou tardes, para poder passar para o problema seguinte.

São várias as formas de avaliação possíveis dentro do currículo baseado em problemas. São previstas avaliações por módulos, avaliação progressiva dos conhecimentos dos alunos, avaliação das habilidades esperadas em cada série $e$ avaliações informais, em que se observam as atitudes dos alunos. Com relação à avaliação realizada ao final de cada módulo temático, lê-se na Home Page da UEL (1997):

...tem por finalidade principal avaliar a qualidade do módulo. Um módulo temático deve levar os alunos a atingirem determinados objetivos de conhecimento. O núcleo central do módulo temático são os problemas desenvolvidos para a abordagem dos temas. Um bom problema deve ensejar uma boa discussão no grupo tutorial de modo que ao fim desta discussão os alunos elejam objetivos de aprendizado adequados ao conhecimento do tema em estudo. (http://www.uel.br/uel/pbl/)

Não vamos esgotar aqui todas as características de um currículo baseado em problemas. Vamos acrescentando mais algumas no item a seguir, mas vale lembrar que para seu gerenciamento, várias comissões são necessárias, como a Comissão de Currículo, a Comissão de Avaliação, as Comissões Diretoras e outra que nos interessa ressaltar, a Comissão de Proposição de Problemas. 
Esta Comissão deve reunir um grupo habilitado na técnica de propor problemas adequados ao desenvolvimento dos temas elaborados pela Comissão de Currículo.

\section{Características comuns e diferenciadoras das duas propostas.}

Como percebemos pelo já descrito, temos aqui duas propostas metodológicas bem diferentes. A primeira, como uma metodologia que pode ser utilizada para o ensino de determinados temas de uma disciplina, nem sempre apropriada para todos os conteúdos; a segunda, como uma metodologia que passa a direcionar toda uma organização curricular.

Dentro desta perspectiva, as duas propostas assumem dimensões distintas, porque a primeira é uma opção do professor e a segunda é uma opção de todo um corpo docente, administrativo e acadêmico, já que as conseqüências afetam a todos, durante todo o curso.

Como decorrência da opção feita pela Aprendizagem Baseada em Problemas, definem-se porções de conteúdos, que serão tratados agora de modo integrado, definem-se modos de agir para ensinar, para aprender, para administrar, para apoiar, para organizar materiais ... Há necessidade de providências quanto à biblioteca, que deve ser suficientemente equipada e espaçosa, horários e organização de laboratórios, para as atividades opcionais, distribuição de temas versos tempo, etc. Enfim, definem-se novos papéis para serem desempenhados por todos os envolvidos. Todas essas características são bastante distintas dos moldes tradicionais de ensinar e aprender e da organização curricular a que a maioria quase absoluta das escolas estão acostumadas.

A opção pela Metodologia da Problematização não requer grandes alterações materiais ou físicas na escola. As mudanças são mais na programação da Disciplina . Requer sim alterações na postura do professor e dos alunos para o tratamento reflexivo e crítico dos temas e na flexibilidade de local de estudo e aprendizagem, já que a realidade social é o ponto de partida e de chegada dos estudos pelo grupo de alunos.

Os problemas constituem um dos pontos comuns das duas propostas, mas como já procuramos demonstrar antes (Berbel, 1994) e pelo acima descrito, fica 
clara a abordagem distinta dos problemas pelos integrantes do processo de ensino-aprendizagem.

Na Metodologia da Problematização, os problemas são identificados pelos alunos, pela observação da realidade, na qual as questões de estudo estão acontecendo. Observada de diferentes ângulos, a realidade manifesta-se para alunos e professores com suas características e contradições, nos fatos concretos e daí são extraídos os problemas. A realidade é problematizada pelos alunos. Não há restrições quanto aos aspectos incluídos na formulação dos problemas, já que são extraídos da realidade social, dinâmica e complexa.

Na Aprendizagem Baseada em Problemas, os problemas são cuidadosamente elaborados por uma Comissão especialmente designada para esse fim. Deve haver tantos problemas quantos sejam os temas essenciais que os alunos devem estudar para cumprir o Currículo, sem os quais não poderão ser considerados aptos para exercer a profissão. E, como lemos em Sakai e Lima(1996), devem "consistir de uma descrição neutra do fenômeno em estudo, ser isento de distrações e ainda serem completamente entendidos de um ponto de vista científico" (grifos nossos).

A Aprendizagem Baseada em Problemas tem uma seqüência de problemas a serem estudados. Ao término de um, inicia-se o estudo do outro. O conhecimento adquirido em cada tema é avaliado ao final de cada módulo, com base nos objetivos e nos conhecimentos científicos.

Na Metodologia da Problematização, após o estudo de um problema poderão surgir outros, como desdobramentos do primeiro, só percebidos pelos alunos com o estudo aprofundado deste. Os conhecimentos científicos também são importantes e são buscados na etapa da teorização. No entanto, ao mesmo tempo são buscadas as percepções ou representações de pessoas que vivem o problema ou convivem com situações em que está presente, além de informações de outras fontes. Os diferentes tipos de saberes são conjugados pelos alunos enquanto constróem seus conhecimentos, que envolvem relações entre o técnicocientífico e o social, político, ético...

Pela própria responsabilidade em garantir os conhecimentos mínimos exigidos pelo Currículo, na Aprendizagem Baseada em Problemas os objetivos cognitivos são todos previamente estabelecidos e os construídos pelos estudantes deverão coincidir com os dos especialistas do Currículo. Em caso contrário, os problemas devem ser substituídos para que se encontrem outros mais efetivos para provocar tais aprendizagens. 
Na Metodologia da Problematização não há controle total dos resultados em termos de conhecimentos. Eles são buscados para responder ao problema em estudo, este entendido amplamente, considerando-se suas possíveis causas $e$ determinantes, que em geral ultrapassam os aspectos técnico-científicos. Os resultados não são de todo previstos, a não ser em termos da vivência das atividades pelo aluno em todas as etapas do processo. Os conteúdos tanto podem não satisfazer ao professor em termos do que gostaria de ver apreendido pelos alunos, quanto podem surpreender ao professor e ao próprio grupo quando descobrem aspectos e relações não previstos. Se ocorre o primeiro caso, o professor poderá / deverá providenciar outra forma e momento para suprir o essencial do programa não atingido naquele tema.

Ambas incluem hipóteses a serem formuladas pelos alunos. Na Aprendizagem Baseada em Problemas, as hipóteses são elaboradas pelos alunos sobre as possíveis explicações do problema

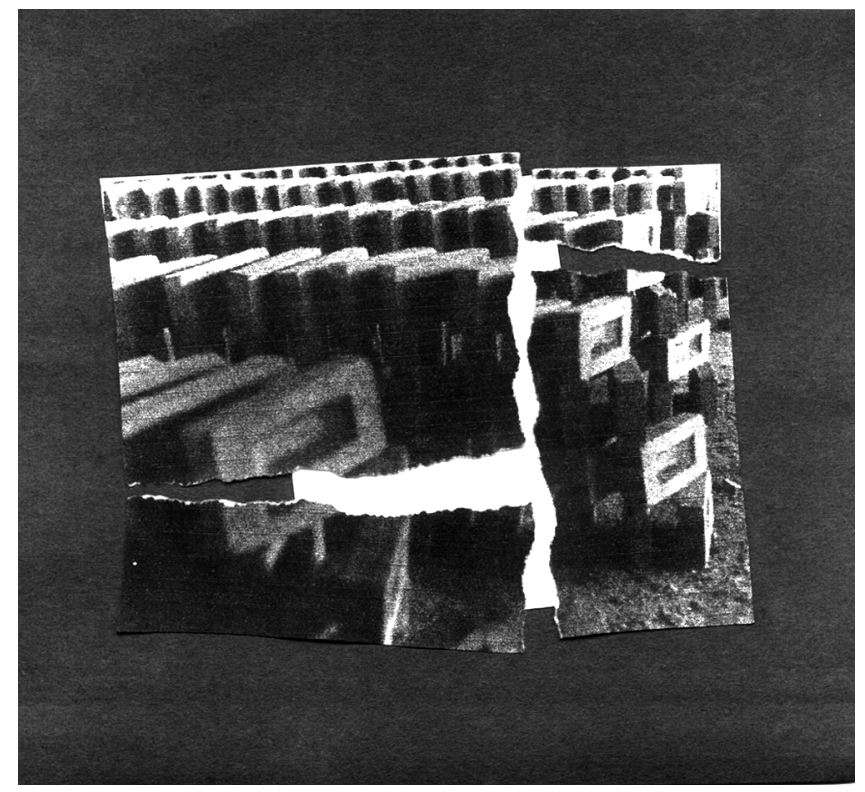
antes de seu estudo, como uma forma de estimulá-los a partir dos conhecimentos que já dispõem, pelas suas experiências anteriores.

Na Metodologia da Problematização há um momento semelhante a este, mas aí os alunos analisam as possíveis causas e possíveis determinantes maiores do problema a estudar. As explicações não são somente relacionadas aos conhecimentos técnico-científicos. Este é um momento crítico de buscar captar relações sociais, políticas, econômicas... Também aí os alunos partem de seus conhecimentos prévios, que poderão ser comprovados ou reformulados pelo estudo na Teorização. As hipóteses, porém, são formuladas após o estudo, quando já contando com informações científicas, técnicas, legais, históricas, empíricas ou outras, formulam as hipóteses de solução, que orientarão a intervenção na realidade da qual se extraiu o problema. 
Ambas as propostas incluem também o trabalho em grupo. Na Metodologia da Problematização, o grupo trabalha junto o tempo todo, com a supervisão de um professor. Em alguns momentos poderão distribuir tarefas, mas retornam sempre para o grupo, que vai construindo o conhecimento através das etapas do Arco. Na Aprendizagem Baseada em Problemas, o grupo inicia junto o conhecimento e discussão do problema e retorna depois para a rediscussão no grupo tutorial, quando os estudos individuais já foram feitos. Professores especialistas podem ser consultados durante o estudo.

$\mathrm{Na}$ Metodologia da Problematização, os estudos ocorrem na etapa da Teorização, quando se buscam as informações sobre os pontos-chave, onde quer que elas se encontrem, contando para isso com o uso de técnicas e instrumentos de coleta de dados usuais na pesquisa científica, mas podendo utilizar também recursos não convencionais, como depoimentos escritos, orais etc., quando significativos para compreensão do problema.

Na Aprendizagem Baseada em Problemas, o estudo se dá essencialmente na biblioteca, quando os alunos buscam atingir os objetivos cognitivos que elaboraram para alcançar, a partir dos problemas.

Deste modo, é possível entender que a Aprendizagem Baseada em Problemas lança mão do conhecimento já elaborado para aprender a pensar e raciocinar sobre ele e com ele formular soluções para os problemas de estudo. A Metodologia da Problematização, além disso, é um desafio para a construção de novos conhecimentos, pela aproximação da realidade em que o tema em estudo é vivido por diferentes atores sociais.

Há também uma grande diferença quanto ao uso dos resultados dos estudos. Na Aprendizagem Baseada em Problemas, os conhecimentos serão utilizados para resolver os problemas como exercício intelectual e nas práticas de laboratório el ou com pacientes.

Segundo Thomson (1996,p.7), além dos objetivos cognitivos "é dada muita importância à aquisição de habilidades, através de aprendizagem em modelos, pacientes simulados, observação intensa do que é normal e também a aprendizagem de habilidades dos estudantes com os estudantes".

Para a resolução dos problemas, no entanto, o estudo individual é importante para a retenção dos conhecimentos. Após o estudo individual pelos alunos, esses resultados são apresentados e discutidos no grupo tutorial, a partir do que estarão preparados para serem avaliados no final do módulo. Inicia-se, então, o estudo de outro problema. 
Na Metodologia da Problematização os resultados deverão voltar-se para algum tipo de intervenção na realidade, na mesma realidade na qual foi observado o problema, imediatamente, dentro do nível possível de atuação permitido pelas condições gerais de aprendizagem, de envolvimento e de compromisso social do grupo.

A etapa da Aplicação à Realidade é uma etapa prática e transformadora. $\mathrm{O}$ grau de intervenção depende de vários fatores, mas alguma intervenção deve ocorrer ou então não será a Metodologia da Problematização, com os passos do Arco de Charles Maguerez.

Percebe-se assim que tanto o ponto de partida quanto o ponto de chegada das duas propostas são diferentes e é possível que a explicação maior esteja em seus fundamentos teóricos.

Vimos explicando e desenvolvendo a Metodologia da Problematização como uma alternativa metodológica que busca mediar a concepção Histórico-Crítica da Educação e o trabalho pedagógico do professor com seus alunos (Berbel, 1995 e 1996). Encontramos para isso respaldo na Filosofia da Praxis (Adolfo Sanchez Vazquez) e na Pedagogia Libertadora/Problematizadora (Paulo Freire e outros), com inspiração nos princípios do Materialismo Histórico Dialético. A máxima ação-reflexão-ação transformadora é o eixo básico de orientação de todo o processo.

A Aprendizagem Baseada em Problemas tem como inspiração os princípios da Escola Ativa, do Método Científico, de um Ensino Integrado e Integrador dos conteúdos, dos ciclos de estudo e das diferentes áreas envolvidas, em que os alunos aprendem a aprender e se preparam para resolver problemas relativos à sua futura profissão.

Por todas essas razões cremos ser possível afirmar que Problematização $e$ Aprendizagem Baseada em Problemas não são apenas dois termos, mas dois caminhos diferentes de ensino e de formação profissional, com diferentes conseqüências.

O Curso de Medicina da UEL implantará, em 1998, uma nova proposta curricular com a opção pela Aprendizagem Baseada em Problemas, para a organização dos primeiros quatro anos de formação.

Paralelamente a essa inovação, para um curso que completa 30 anos em 1997, a comissão responsável pela organização da proposta se lança também o 
desafio de incluir como atividade curricular o Projeto Especial de Ensino (PEEPIN) que se desenvolve com alunos dos cinco cursos da área da saúde na UEL desde 1992 e que se utiliza da Metodologia da Problematização para essa atividade acadêmica.

Mesmo sendo dois caminhos, foram considerados compatíveis pela Comissão de desenvolvimento do novo currículo, por valorizarem a experiência com a Metodologia da Problematização como "adequada para o desenvolvimento da interação de professores e alunos no desempenho de atividades de ensino $e$ pesquisa nos cenários de ensino comunitários e dos serviços de saúde” (Projeto... 1997, p.12).

Esta abertura é sem dúvida nenhuma promissora. O entendimento profundo do potencial de cada uma dessas propostas provavelmente permitirá uma atuação docente criativa, crítica e também cada vez mais conscientemente política (no sentido da postura político-pedagógica).

Por último, podemos reforçar que o conhecimento das características das duas propostas como as ensaiadas aqui, as já descritas em outros textos e muitas outras que podem ser descobertas com a experiência, não permitirá confundi-las, mas com certeza tomá-las como alternativas inspiradoras de um Ensino Superior inovador, que ultrapasse a insistente abordagem tradicional. Além disso, devemos considerar que

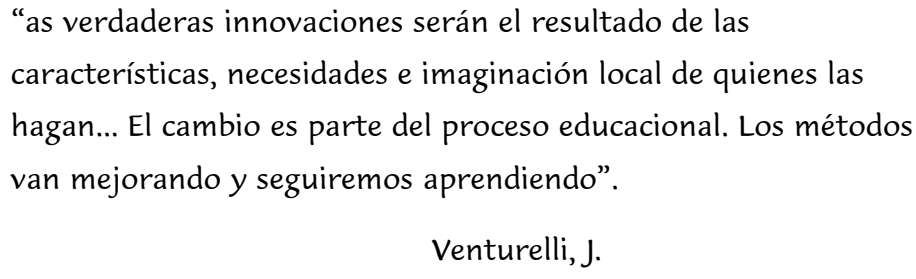

\section{Referências bibliográficas}

BERBEL, N. A. N. Metodologia da Problematização no Ensino Superior e sua contribuição para o plano da praxis. Semina : v.17, n. esp., p.7-17, 1996. Metodologia da Problematização : uma alternativa metodológica apropriada para o Ensino Superior. Semina : Londrina, v. 16, n. 2, n esp., p.919, 1995. 
BORDENAVE, J. ; PEREIRA, A. Estratégias de ensino aprendizagem. 4. ed., Petrópolis: Vozes, 1982.

COMISSÃO de Desenvolvimento do Novo Currículo de Medicina. Problem Based

Learning - Centro de Ciências da Saúde - UEL. 1997. [Online] Available: http:// www.uel.br/uel/pbl/

PROJETO do Novo Currículo do Curso de Medicina. 1998. Londrina: UEL. PROUNI, 1997. $30 \mathrm{p}$.

SAKAI, M. H.; LIMA, G.Z. PBL: uma visão geral do método. Olho Mágico, Londrina, v. 2, n. 5/6, n. esp., 1996.

THOMSON, J.C. PBL - uma proposta pedagógica. Olho Mágico, Londrina, v. 2, n. 3/4, 1996.

VENTURELLI, J. Educación Médica y en Ciencias de la Salud; Inminencia y necesidad del cambio. [s.l.] : Facultad de Ciencias de la Salud, Universidad de Macmaster, (s.d.). 